\title{
IGLESIA Y VIOLENCIA EN TORNO A LA IDEA DE CRUZADA (SIGLO XII)
}

\author{
POR
}

\author{
Carlos de Ayala Martínez
}

Universidad Autónoma de Madrid

\section{ResUmen}

El artículo consta de dos partes. En la primera se hace un rápido repaso de la actitud de la lglesia ante el tema de la violencia, analizando de manera muy breve las distintas fases por las que atraviesa la institución en relación al tema, desde sus inicios al siglo'XII, momento en que el fenómeno, debidamente integrado, alcanza plena justificación. En la segunda parte, centrada cronologicamente en esa misma centuria, se aborda el tema de los áltimos vestigios de «pacifismo eclesíastico, analizados desde la perspectiva de la crítica a las Órdenes militares.

\section{AbSTract}

\section{Church and Violence about the crusade idea}

This article is composed of two parts. In the first it is made a quick revision of Catholic Church's posture with regard to violence, briefly analysing various stages of this pasture since the patriste beginnings till Twelfth Century, a moment in which the violence's topic was properly justified and integrated in the Church's dogmatic structure. In the second part, chronologically focused in this samen moment, the Twelfth Century, it is approached the matter of the late ecclesiastic pacifism's vestiges, analysed in close relationship with the movement of critic towards the Military Orders.

\footnotetext{
I El contenido de estas páginas constituye la aportación del autor al curso Las Cruzadas en su Centenario desarrollado, bajo la dirección del profesor Luis Suárez Fernández, en El Escorial, en julio de 1996.
}

Sobre 1a Iglesia Medieval Hispania Sacra 49 (1997) 


\section{PResentación}

Un conocido sermón, redactado en la primera mitad del siglo XIV por el freire santiaguista Pedro López de Baeza, y que lleva por título Qué significa el ábito que traen los freires de Santiago, contiene la siguiente frase explicativa: ... E la espada que es vuestro ábito significa muchas cosas. La primera es la señal de la cruz que vos traedes en los pechos, e significa aquella mesma vera cruz en que Jesu Cristo puso las sus espaldas e en que murió por los nuestros pecados lavar... ${ }^{2}$ Como vemos, una perfecta identificación de contenido alegórico entre espada y cruz.

La pregunta que se plantea resulta evidente: ¿como se pudo llegar, desde el Evangelio, a esta identificación? Ciertamente, entre las proclamas pacíficas y pacificadoras de los evangelios canónicos -escritos todos ellos entre los años $65-70$ y 100 - y la identificación simbolica de espada y cruz que encuentra en este sermón santiaguista una plástica e incluso razonada expresión, median más de 1000 años de una evolución compleja y apasionante, una evolución que llega a su consumado corolario a través del movimiento cruzado de los siglos XI y XII.

Nos serviremos de esta reflexión inicial para plantear muy brevemente dos cuestiones concatenadas entre sí y ambas de indiscutible interes: la transformación de la actitud de la Iglesia en relación al tema de la violencia, y la persistencia de una corriente crítica hacia la progresiva justificación de esa violencia, centrada en lo que aparecía como su más acabada materialización, las Órdenes militares.

\section{TRANSFORMACIÓN DE LA ACTITUD DE LA IGLESIA EN RELACIÓN AL TEMA DE LA VIOLENCIA}

\section{a) Explicación del fenómeno: relaciones Iglesia-poder político}

Es abundante ta historiografía que ha abordado el tema de la transformación de la actítud de la Iglesia en relación al problema de la violencia. Sin querer caer en reduccionismos, inadmisibles ante tan compleja cuestión, pensamos que no es difícil relacionar de manera directa esa transformación que va desde la más absoluta condena hasta la santificación circunstancial, con la cambiante posición de la Iglesia respecto al poder constituido: una posición de

2 Publ. LomaX, D.W. «Pedro López de Baeza. "Dichos de los Santos Padres" (siglo XIV)», en Miscelánea de Textos Medievales, 1 (1972), p. 176.

Sobre la Iglesia Medieval Hispania Sacra 49 (1997) 
radical alejamiento en sus primeros siglos de existencia, para pasar, en los siglos centrales de la Edad Media, a ser ella misma fuente excluyente de poder. Podemos, en este sentido, calibrar una evolución vertebrada en cinco etapas fundamentales:

1. Antes de 313, la Iglesia, marginada en líneas generales de la gestion del poder, se mantiene radicalmente fiel al pacífico mensaje evangélico, reforzada en sus posiciones por un permanente ejercicio de autoafirmación frente a los contravalores del régimen imperante, basados en buena medida en la fuerza militar.

2. Cuando en el transcurso del siglo IV la Iglesia pasa de ser tolerada a incorporarse de manera consustancial al cuerpo político, su discurso sobre la violencia se matiza. Ciertamente, la postura general sigue siendo contraria a ella, y es que la participación de 1a Iglesia en el gobierno, no anula el carácter eminentemente civil de éste; es por ello por lo que la Iglesia, en su afán por atemperar el fuerte componente secular del Estado, demasiado dependiente de postulados militaristas, adopta una posición de evidente recelo hacia ellos.

Si nos fijamos, por ejemplo, en la paradigmática figura de san Agustín, no podemos, ciertamente, hablar de antimilitarismo y mucho menos de "pacifismo», pero su decidida actitud de distanciamiento respecto al poder civil, desaconsejando que los obispos asumieran las responsabilidades que el poder secular deseaba delegar en ellos, es muestra patente de la voluntad de no implicar a la Iglesia en las tareas ordinarias de gobierno y en la coactiva materialización de las mismas ${ }^{3}$.

3. La etapa germánica es, en muchos sentidos, deudora de los siglos bajorromanos. También lo es en relación al tema que nos ocupa. Hay que esperar a la fase carolingia para percibir cambios importantes. La coparticipación de la Iglesia, en teórico pie de igualdad con las instancias seculares, en el entramado político desplegado por los carolingios antes y después de

3 Touchard, J. Historia de las ideas politicas, Madrid, 1972, p. 101. No debemos ver en ello, sin embargo, una sactitud pacifistas. De hecho, cuando en el siglo XI el canonista Anselmo de Lucca, por encargo de Gregorio VII, se dedic6 a reunir materiales que justificaban el uso de la guerra desde una optica cristiana, hubo de acudir para ello a los santos padres y, de manera muy especial, a san Agustin; el resultado fue la Collectio Canonum (c. 1083), arsenal de citas patristicas de donde es posible deducir que la guerra bien entendida y debidamente controlada por la Iglesia puede ser una auténtica manifestación de amor y caridad (STICKLER, A. all potere coattivo materiale della Chiesa nella Riforma Gregoriana secondo Anselmo di Luccan, en Studi Gregoriani, 2 (1947), pp. 235-285; RILEY-SMFTH, J. «Crusading as an Act of Love», en History, 65 (1980), pp. 185-189, y del mismo autor, The First Crusade and the ldea of Crusading. Londres, 1993, pp. 5-6).

Sobre la Iglesia Medieval Hispania Sacra 49 (1997) 
la instauración del Imperio, comienza a desplazar la posición de la Iglesia hacia posturas no sólo más comprensivas con la violencia, sino incluso claramente justificadoras de la misma. Aún no nos hallamos ante una sistemática legitimación de la agresión, pero sí ante la sacralización del valor misional de la guerra y, por supuesto, de la justificada defensa armada.

Richard Barber subraya la imagen que todavía la hagiografía del siglo $\mathrm{X}$ nos trasmite sobre san Edmundo, el santo rey anglosajón martirizado por los daneses en 870, una imagen pasiva, ajena en todo a la bravura del soldado. Sin embargo, y según señala el propio autor, no faltan para entonces, y desde el siglo VIII, ejemplos de una decidida postura eclesiástica activa en relación al tema de la agresión armada, siempre que la justificación mediante fines sagrados aparezca claramente expresada. El autor concede, en este sentido, especial importancia al influjo germánico y a la extensión de su mitología guerrera, ahora convenientemente cristianizada. ${ }^{4}$

4. Conforme avanza el siglo $X$, el Occidente postcarolingio, alejado de cualquier formulación unitaria de resonancias estatales, se ve inmerso en una progresiva e imparable fragmentación feudalizante, que solo el referente eclesiástico es capaz de neutralizar. El orden se identifica con la Iglesia, y ésta desarrolla cauces normalizadores que aseguren la regulación de la violencia y, en cualquier caso, el monopolio de su sanción legitimadora.

Como es bien conocido, el movimiento de la Paz de Dios es una primera respuesta, avalada por la Iglesia, frente a la anarquía que la fragmentación del orden político había provocado. En torno al año 1000 , clérigos, algunos obispos y, sobre todo, la Orden de Cluny sostuvieron iniciativas, conciliarmente sancionadas, que venían a señalar a la Iglesia como auténtico árbitro y protector, al tiempo, de la sociedad civil. El éxito del movimiento animó a sus responsables a llevar a la práctica auténticos programas de regulacion de la violencia a través de la institución de la Tregua de Dios. ${ }^{5}$

5. El proceso, finalmente, se consuma entre la segunda mitad del siglo XI y la primera del XII. Un pontificado fuerte, capaz de encarar el fiderazgo de la señorializada y fragmentada Europa, asume la responsabilidad de la defensa y expansión de la Cristiandad. La violencia pasa, así, a ser justificada en su faceta agresiva, siempre y cuando obedeciera a los sagrados intereses de la Iglesia. Se trata de una manifestación más de la teocracia pontificia en su lucha por el Dominium Mundi.

4 BARBER, R. «The Church, Warfare and Cusades», en The Knight and Chivalry, Woodbridge, $1995^{3}$, p. 250.

5 COWDRY, H.E.J. «The Peace and the Truce of God in the Eleventh Century», en Past and Present, 46 (1970), pp. 42-67. 


\section{b) Justificación del fenómeno: Antiguo Testamento, Pontificado y Cruzada}

El proceso de sacralización de la violencia puede ser explicado de este modo, pero en su momento fue preciso ampararlo mediante un sólido aparato doctrinal que le sirviera de justificación. La fuente legitimadora no podía ser otra que la Biblia, y de manera especial el Antiguo Testamento. No hay que olvidar que, como dice Giulio Cipollone, la guerra conecta plenamente con la Antigua Alianza, no con la Nueva. ${ }^{6}$ No faltan autores que han intentado demostrar, sin duda con fundamento sólido, cómo a partir de los siglos VII y VIII el Antiguo Testamento irrumpe en la vida política, adecuando, como mecanismo de reforzamiento legitimador, el modelo de la teocracia real veterotestamentaria a la emergente realidad de las monarquías altomedievales. El esquema, en lo que se refiere a estructuras monárquico-seculares, pudo irse perfeccionando en épocas más avanzadas. ${ }^{7}$

Pero lo que realmente nos interesa destacar aquí es la progresiva apropiacín por parte de la Sede Apostólica de principios veterotestamentarios que llegaron, en buena medida, a justificar las pautas de su expansivo liderazgo sobre una Cristiandad, asimilada en muchos aspectos al pueblo de Israel: un pueblo elegido por Dios, aliado a Él mediante pacto sagrado, acaudillado por un líder indiscutible que lo conduce, con mano fuerte y a través de una liberadora experiencia no exenta de confrontaciones armadas, a la sagrada tierra de promisión. Una imagen, como puede verse, fácilmente extrapolable al movimiento cruzado: el pueblo de Dios, liderado por la sacral figura del Papa, se pone en marcha, mediante un liberador proceso de purificación -el peregrinaje armado-u, para alcanzar la meta material, pero también escatologica, de la Jerusalén prometida. ${ }^{8}$

El proceso de lo que algunos han calificado como el monopolio papal de la Biblia, ${ }^{9}$ cuenta con una cronología relativamente precisa, en la que destacaremos un punto de partida, las precursoras doctrinas bíblicas del universalismo

6 Cipollone, G. «La parole, les paroles de Dieu: la guerre sainte (1187-1216)m, en PH. CONTAMINE Y O. GUYOTJEANNIN, La guerre, ta violence et les gens au Moyen Age. 1 . Guerre et Violence, Paris, 1996, p. 26.

7 ULLmanN, W. «The Bible and Principles of Government in the Middle Age», en Settimana di Studio Spoleto, Spoleto, 1963, pp. 181-228.

8 Son muchísimos los autores que venido subrayando esta identificación legitimadora de imágenes veterotestamentarias con fa realidad del movimiento cruzado. Vid., por ejemplo, RILEY-SMITH, The First Crusade, pp. 91.92.

9 UllmanN, W. Historia del pensamiento politico en la Edad Media, Barcelona, 1983, p. 76 (con referencia a E. Kantorowicz). 
papal en Nicolás I (858-867), ${ }^{10}$ y un espléndido colofón: el Decretum de Graciano, que, a mediados del siglo XII, eleva el Antiguo Testamento a la categoría de auctoritas legitimadora, parangonable a la de los Santos Padres." "

De este modo, el camino estaba ya más que expedito para que poco antes de 1150 san Bernardo acudiera a la historia de los hebreos a la hora de justificar la cruzada y explicar su circunstancial derrota, y también, desde luego, para que los primitivos cronistas de las cruzadas concibieran las Gesta Dei como una mera continuación de las guerras del Dios de Israel. ${ }^{12}$ Por su parte, los decretalistas envolvieron la cruzada en un tranquilizador armazón jurídicoformal que hacía de ella el mejor y más completo ejemplo de guerra santa, manifestación específica, a su vez, de la guerra justa.

James A. Brundage explica muy bien este último proceso. Según su autorizada opinión, Graciano y los decretalistas del siglo XII aportaron una elaborada clasificación terminológico-conceptual que distinguía, en primer lugar, entre violencia privada y pública. Esta última, a su vez, podía ser profana o sagrada. La violencia pública sagrada se correspondía con la guerra justa, que podía practicarse tanto en defensa del reino, de la familia y de la legítima propiedad, como en defensa de la Iglesia y de la religión cristiana. En este último caso, nos encontramos con la guerra santa, de la que la cruzada no es más que una manifestación.

En efecto, eran posibles diversas modalidades de guerra santa. Para que una cruzada fuera canónicamente reconocida como tal, pasaba por presentar las siguientes características: 1) A diferencia de otras guerras santas que podían ser predicadas por los obispos en virtud del ius gladii que poseían, la cruzada solo podía ser proclamada por el Papa. 2) Solo a él correspondía, además, autorizar la concesión de indulgencia plenaria. 3) Los cruzados, y no otros participantes en guerras santas, se juramentaban mediante la emisión de votos. 4) Gozaban, además, mientras duraba la cruzada, de determinados privilegios temporales: protección sobre sus personas, familia y propiedades, inmunidades semejantes a las de los clérigos y ciertas exenciones fiscales. 5) Solo los cru-

10 UllmanN, W. ibid.; ID., Principios de gobierno y politica en la Edad Media, Madrid, 1971, p. 56.

"Diccionario Enciclopédico Bíblico, bajo la dirección del Centro «Informática y Bíblica» de la Abadia de Maredsous, Barcelona, 1993, p. 475.

Sobre la presencia de la eautoridad bíblica» en las colecciones canónicas en general, vid. GAUDEMET, J. «La Bible dans les collections canoniques», en P. RICHÉ-G. LOBRICHON (eds.), Le Moyen Âge et la Bible, Paris, 1984, pp. 327-369. Vid. igualmente las reflexiones introductorias de GarCía Y GarCí, A. «La Biblia en el Concilio IV Lateranense», en Iglesia, Sociedad y Derecho, Universidad Pontificia de Salamanca, 1987, pp. 238-242.

12 CIPOLLONE, art. cit., p. 28.

Sobre la Iglesia Medieval Hispania Sacra 49 (1997) 
zados podían combatir bajo la enseña de la cruz, como símbolo y manifestación de su específico status. ${ }^{13}$

\section{RESIDUOS DE «PACIFISMO» EN LA IGLESIA: LA CRÍTICA A LAS ÓRDENES MILITARES}

A mediados del siglo XII la justificación de la guerra no supone ya ningún problema para la Iglesia. No es extraño que sea entonces cuando inicien su andadura las Órdenes militares, de las que se ha dicho - y obviamente no falta razón para ello- que son el más claro ejemplo de esa integración gradual en los esquemas de justificación eclesiástica del uso de la violencia como legítimo instrumento de la sociedad cristiana.

Este hecho, sin embargo, no nos puede hacer perder de vista que la vena «pacifista» no se había agotado del todo en el seno de la Iglesia, y que, en mayor o menor relación con ella, no faltaron voces que, desde el mismo siglo XII, se alzaron contra las funciones encomendadas a las Órdenes militares e incluso contra su propia existencia. No se trata de una importante corriente de opinión, no lo es, al menos, desde el punto de vista cuantitativo, y presenta, además, distintos enfoques e intensidades muy diversas, pero conviene recoger algunos de sus ejemplos más representativos.

De hecho, cuando hablamos de crítica a las Órdenes militares, lo estamos haciendo de una realidad heterogénea, de un frente crítico muy amplio y diverso que no siempre conecta con ese presunto o real pacifismo al que venimos aludiendo. En realidad, grosso modo, podemos distinguir hasta cuatro tipos de críticas que ciertamente se relacionan entre sí, pero que obedecen a cuestiones y circunstancias de diversa naturaleza.

1.- En primer lugar, nos encontramos con lo que podríamos definir como «crítica económica». Las Órdenes militares irrumpen con fuerza -y protección real o papal- en el nutrido mosaico de obediencias y disciplinas religiosas, casi superpoblado a raíz del reformismo gregoriano, reclamando derechos y privilegios en pie de igualdad con ellas. El clero secular - y a su cabeza los obispos-y los propios monjes ponen el grito en el cielo: diezmos, derechos de sepultura y otras rentas debían ser repartidas. Era preciso crear una cierta imagen descalificadora de los freires que, al menos, los convirtiera en inferiores a las tradicionales formas de vida religiosa y que, por consiguiente, no les hiciera acreedores de los privilegios de aquéllas. Lo mejor era tildarlos de co-

13 BRUNDAGE, J.A. «The Hierarchy of Violence in Twelfth -and Thirteenth-Century Canonists", en The International History Review, XVIl (1995), en especial pp. 680-681. 
diciosos, más preocupados de recaudar rentas que de combatir al infiel. No es ésta, desde luego, la crítica que conecta con la minoritaria realidad «pacifista» de la Iglesia, pero debemos detenemos mínimamente en ella.

Juan de Salisbury y su Policraticus es un buen ejemplo de esta actitud crítica, fundamentalmente preconizada por el clero secular. También lo es el arzobispo Guillermo de Tiro en su Historia Rerum in Partibus Transmarinis Gestarum. Sus críticas anteceden de manera inmediata, y tambien ilustran, las prescripciones restrictivas hacia los derechos de las Órdenes militares aunque no sólo de ellas- que fueron promulgadas en el III Concilio de Letrán de 1179. ${ }^{14}$ Éste fue, en efecto, especialmente duro en este sentido, de manera particular con templarios y hospitalarios a los que específicamente cita, individualizando en su contra críticas concretas: a fin de cuentas existía la extendida convicción de que los freires representaban una dimensión de inferior espiritualidad respecto a las formas tradicionales de vida religiosa, y ello hacía que el disfrute por su parte de ciertos privilegios fuera especialmente injustifica$\mathrm{do}^{15}$. El resultado de la segunda cruzada no ayudo a minimizar las posiciones conciliares que se repetirán en ulteriores sínodos nacionales y concilios ecuménicos en el transcurso de los siglos XII y XIII' ${ }^{16}$.

2.- Se detecta, en segundo lugar, lo que no sería demasiado incorrecto definir como «crítica política». El poder económico de las Órdenes militares ha generado en su beneficio auténticas plataformas de poder político que hacen de ellas pequeños y desafiantes «estados dentro del estado». Uno de los motivos profundos del proceso de los templarios fue éste, pero desde mucho antes destacadas personalidades que ejercían responsabilidades políticas llamaron la atención sobre el tema. Era preciso fomentar la creación de una imagen para las Órdenes militares que respondiera al arquetipo de la soberbia y del orgullo: institutos más preocupados por acrecentar sus cuotas de poder que por combatir a los musulmanes.

En el XII, el citado arzobispo Guillermo de Tiro, prelado y canciller del reino de Jerusalén, había llamado ya la atención sobre la desafiante actitud que las Órdenes militares adoptaban frente a los poderes real y patriarcal, las dos columnas que sostenían el régimen latino. Para el arzobispo Tierra Santa sólo podía ser

14 GarCia-Guijarro Ramos, L. Papado, Cruzadas y Órdenes militares. Siglos XI-XIII, Madrid, 1995, pp. 151-156.

is El texto del Lateranense III alusivo a templarios y hospitalarios, en G.D. MANSI, Sacrorum Conciliorum Nova et Amplissima Collectio, XXII, Venecia, 1778, cols. 222-224.

16 NiCHOLSON, H. Templars, Hospitallers and Teutonic Knights. Images of the Military Orders, 1128-1291, Leicester University Press, 1993, p. 41. 
eficazmente defendida por nobles laicos, ya que los freires, obstinados en rivalizar con ellos, significaban más un obstáculo que una vía de solución. ${ }^{17}$

Pero la «crítica política» poseía otras dimensiones. Por ejemplo, la derivada de la participación de las Órdenes militares en los conflictos entre el Imperio y el Papado. El cronista Mateo París (1200-1259), monje de la abadía benedictina de St. Albans, y convencido germanófilo, creía que templarios y hospitalarios habían perjudicado la causa cristiana en Tierra Santa por su oposición al emperador Federico II. Su opinión, sin embargo, quedaba muy matizada al referirse a la Orden Teutónica, aliada del Emperador. ${ }^{18}$

Tampoco es ésta la crítica que conecta con la marginal sensibilidad «pacifista» de la Iglesia, y sin embargo, y en la medida que venía a subrayar el carácter soberbio y marcadamente secularizante de los freires, este tipo de crítica -bien es verdad que depurada de sus más sofisticadas connotaciones políticas- constituyó un duradero filón de referęncia en la conciencia de un sector determinado de la población. Baste recordar aquí al popular predicador británico de origen normando, Odo de Cheriton, autor de unas Fábulas escritas poco después de $1225,{ }^{19}$ y cuya versión romanceada nos llegaría a Castilla a través de los «exiemplos» contenidos en el anónimo Libro de los Gatos compuesto en Castilla en torno al año 1400.20

3.- Podemos hablar, en tercer lugar, de una kcrítica militars. Desde relativamente pronto los detractores de las Órdenes militares utilizaron también en su contra el argumento de la pusilanimidad, sumándolo al de la codicia y la soberbia. La supuesta preferencia de templarios y hospitalarios a negociar con los musulmanes que a combatirlos, fue interesadamente interpretada en clave de cobardía. Ahora bien, si las Órdenes militares no servían para combatir, ¿qué es lo que podía justificar su existencia? ${ }^{2 !}$ Obviamente, y con más razón

\footnotetext{
17 Nicholson, ob. cit., pp. 45-46.

18 Jbid., p. 47.

19 Sobre la personalidad de Odo de Cheriton, su estancia en España y la cronología de sus Fábulas, vid. FriEND, A.C. «Mastero Odo of Cheriton», en Speculum, 23 (1948), pp. 641-658.

${ }_{20}$ En las líneas finales del Exiemplo de Galter del Libro de los Gatos se puede leer. ... Igualmente los Templarios, los del Hospital, los de San Juan, si otra cruz no tienen en el corazón, lo que significa mortificar la carne, y si no se guardan del pecado de la carne asi como de la soberbia y de otros pecados, éstos serán como asnos del infierno. Ast los que llevan grandes barbas, cualquier tipo de barbas, nunca entrarb́n en el Paraiso, si no hacen obras que agraden a Dios o no hacen buena vida entre los hombres; y si por tener gran barba se fuese santo, no habria en el mundo nadie más santo que el cabrón. LACARRA, M.J. Cuentos de la Edad Media, Madrid, 1989, pp. 36-44; el texto reproducido, en p. 232 .

21 Las dudas sobre este punto, fueron tomando cuerpo con el tiempo. DEMURGER, A. Auge y calda de los Templarios, 1118-1314, Barcelona, 1986, p. 231.
} 
que en los casos anteriores, esta crítica nada tiene que ver con la «vena pacifista» de la que venimos hablando.

4.- Llegamos así, en cuarto lugar, al punto que nos resulta más interesante, el de la kcrítica moral». ¿Hasta qué punto es lícito que un hombre de religión empuñe la espada y derrame la sangre del prójimo, aunque éste sea un enemigo de la Iglesia?

Este tipo de crítica, la que ahora más nos interesa, nació con las propias Órdenes militares, $y$, en principio, debió estar bastante generalizada, hasta el punto de que afectó a los primeros freires de la Historia, los templarios, invadidos por escrúpulos de conciencia, vacilaciones y temores ${ }^{22}$. San Bernardo hubo de salir al paso en su Elogio de la Nueva Milicia para despejar la duda capital -quien mata a un enemigo de Dios no es un homicida, sino un malici$\mathrm{da}-$ - y la otra duda complementaria: los freires no respondían a la depravada imagen que la Iglesia había generado en tomo a la caballería secular, ellos eran la nueva milicia que la Iglesia necesitaba para el cumplimiento de sus santos fines $^{23}$.

Estas son las dos «críticas morales» que planean en el ambiente: la licitud o no de que un religioso quitara la vida a un semejante, y la conveniencia o no de que un religioso se integrara en un orden secular - la caballería- caracterizado por la violencia. Los mismos argumentos se hallan implícitos en los otros testimonios indirectos de que disponemos, contemporáneos, o de datación cercana, al Elogio de la Nueva Milicia: la carta de Hugo el Pecador y alguna de las misivas de Pedro el Venerable.

En efecto, la carta de Hugo el Pecador dirigida a los freires del Temple nos descubre, en clave de contraofensiva justificadora, muchas de las críticas de que eran objeto por parte de la sociedad. ${ }^{24} \mathrm{La}$ fecha de su redacción no difiere mucho de la de la composición del Elogio de la Nueva Milicia, y hubo quien llegó a identificar al responsable de la misma con Hugo de San Víctor, ${ }^{25}$ si bien, no es descartable que se trate del propio primer maestre, Hugo de Payns. ${ }^{26}$

En la correspondencia del gran abad de Cluny, en efecto, podemos rastrear veladas críticas de que se hace él mismo portador, expresando sus dudas acerca del valor espiritual de la Orden del Temple. Esas dudas aparecen, por ejemplo, en una carta que hacia 1148 dirige al propio maestre del Temple, Ebrard

22 DEMURGER, ob. cit., pp, 41-44.

23. NICHOLSON, ob. cit., p. 37.

24 LECLERQ, J. «Un document sur les débuts des Templiers», en Revue d'Histoire Ecclesiastique, 52 (1957), pp. 81-91.

25 SCHLAFERT, C. «Lettre inédite de Hugues de Saint-Victor aux chevaliers du Temple», en Revue d"Ascetique et Mystique, 34 (1958), pp. 275-299.

26 DUMERGER, ob. cit., p. 43.

Sobre la Iglesia Medieva] Hispania Sacra 49 (1997) 
de Barres. El abad expone al maestre su preocupación por la relajación de votos que muestra un recién ingresado en la Orden del Temple, Humberto de Beaujeau, quien, dicho fuera de paso, mejor haría en combatir a los herejes que merodeaban por la comarca de Cluny que en dedicarse a matar sarrace$\operatorname{nos}^{27}$.

Por otra parte, es de sobra conocida la distinta sensibilidad que, ante los problemas de la época, muestran Pedro el Venerable y el «cruzadista» san Bernardo ${ }^{28}$.

Pero se trata siempre de testimonios -éstos de la $1^{\mathrm{a}}$ mitad del $\mathrm{s}$. XII- indirectos, en que las críticas aparecen sin autoría concreta, salvo en el caso más suave, el del abad de Cluny. Sólo conforme avanza el siglo XII nos encontramos con dos específicas y claramente diferenciables líneas de «crítica moral» cuyos responsables se nos aparecen claramente identificados.

a) Por un lado, nos encontramos con la que vamos a llamar «crítica moral pacifista». Walter Map, un letrado clérigo de la corte inglesa de Enrique II, escribía a finales de los 80, en relación a los templarios, el siguiente juicio: ... para proteger la Cristiandad empuñan la misma espada que le fue arrebatada a Pedro cuando intentaba defender a Cristo... ${ }^{29}$ Este alegato pacifista proviene de un influyente clérigo y un colaborador de la monarquía, pero también de un irónico narrador de historias ${ }^{30}$ que nunca sabemos cuando habla o no realmente en serio. ${ }^{31}$ No pensamos, sin embargo, que asunto tan delicado pudiera ser objeto de chanza, e incluso el propio carácter «popular» de algunas de sus reflexiones nos pondrían sobre la pista de una cierta sensibilidad de la que el sutil arcediano de Oxford no sería sino portavoz. En este sentido, sabemos que un sermón de Jacobo de Vitry de comienzos del XIII —no muy distante en el tiempo de las reflexiones de Map-- contiene una significativa información: no faltaban por aquellos días quienes, desde el Evangelio, rechazaban como ilegí-

27 NiCHOLSON, ob. cit., p. 38.

$28 \mathrm{Cfr}$. FACl, J. «Pedro el Venerable y san Bernardo: reflexiones sobre ura polémica", en Stvdia Historica. $H^{\alpha}$ Medieval, III (1985), pp. 145-156.

29 Cit. FOREY, A. The Military Orders from the Twelfh to the Early Fourteenth Centuries, London, 1992, p. 204. El texto seleccionado por Forey (ex De nugis curialium, I.20, ed. M.R. JAMES, C.N.L. BROOKE and R.A.B. MYNORS, Oxford, 1983, p. 60) recoge otras ideas igualmente interesantes: no es la fuerza lo que debe oponerse a la fuerza, sino la paciencia, pues el legado evangélico no coincide en este punto con las leyes y codigos existentes.

30 Walter Map era arcediano de Oxford y canónigo de San Pablo y de Lincoln. Fue un satírico e inteligente «cuentista», autor de una obra titulada Sobre las patrañas de los cortesanos (De nugis curialium). Pero era, sobre todo, un eficaz colaborador de la Corona: fue justicia itinerante del reino en 1172-1173 y en 1184-1185, además de embajador ante el papa Alejandro III en 1178. W.L. WARREN, Henry $I I$, London, $1991^{3}$, p. 301 , n. 1.

31 NiciJOLSON, ob. cit. p. 39. 
timo el combate, y como inaceptable la presencia de Órdenes militares en el campo de batalla, aunque se tratara de defender a la Iglesia de sus enemigos. ${ }^{32}$

b) Existe, por otra parte, lo que podemos definir como kcrítica moral estratégica». Pero junto a esta minoritaria crítica, fundamentalmente pacifista, y que, en consecuencia, rechaza la existencia misma de las Órdenes militares, va construyéndose, a lo largo ya del siglo XIII - aunque con interesantes antecedentes en la segunda mitad del XII--, una crítica indirecta que no cuestiona esencialmente la violencia, pero que, desde un punto de vista estratégico, se declara contraria a los objetivos radicalmente belicistas de las Órdenes militares. Si dejamos al margen la curiosa personalidad del cisterciense Isaac de la Estrella y de sus irónicas reflexiones acerca de un «quinto evangelio» que permite a cierta nueva caballería extender la fe mediante la fuerza, ${ }^{33}$ esta corriente la sostienen los eternos rivales de las órdenes militares, los nuevos monjes urbanos, mendicantes y predicadores, cuyo espíritu socio-misional resultaba incompatible con la labor militar de los freires. El ejemplo típico es el del franciscano inglés Roger Bacon, quien, en su Opus Maius dirigida al papa Clemente IV, hace una acusadora y muy cruda crítica: la acción devastadora de templarios, hospitalarios y caballeros teutónicos no hace sino impedir la conversión de los musulmanes de Tierra Santa y de los paganos del Bálti$\mathrm{co}^{34}$. En esta misma línea, en 1273, un dominico de Acre, Guillermo de Trípoli, ponía en cuestión, de modo general, la ofensiva cristiana sobre Tierra Santa: las cruzadas, a las que tanto había contribuido a animar más de un siglo antes san Bernardo, constituían un tremendo error que dificultaba la inminente conversión de los musulmanes ${ }^{35}$.

No eran, por tanto, la codicia ni la soberbia de los freires, ni tampoco su cobardía, lo que más preocupaba a dominicos y franciscanos; de hecho, lo que predicadores $\mathrm{y}$, sobre todo, mendicantes venían a cuestionar es la legitimidad

32 FOREY, The Military Orders, p. 204.

33 Isaac de la Estrella era abad del monasterio de este nombre, cercano a Poitiers, entre 1147 y 1169. Las dudas que este filosofo y teólogo expresa acerca de cierta nueva caballería, se refieren, sin duda, al Temple. Patrología Latina, 194, semón 48, col. 1854. Vid. J. LeCLERQ, «Saint Bemard's Attitude Toward Wary, en Studies in Medieval Cistercian History, 2. Cistercians Studies, 24 (1976), p. 29.

34 FOREY, The Military Orders, p. 210 y NiCHOLSON, $a b$, cit., p. 39. Según Nicholson, las criticas van especialmente dirigidas hacia la Orden Teutónica, y es que, en este sentido, existia ya una cierta tradición. En 1222 Honorio II había ordenado a los Hemanos de la Espada, predecesores de los teutónicos en Livonia, que no hostigaran a los nuevos conversos, y en 1240 Gregorio IX se veía en la obligación de recordar las acusadoras críticas que el obispo Christian de Prusia había lanzado contra la Orden Teutónica: impedian el bautizo de los conversos de origen pagano y perseguían a quienes se mostraban sumisos a la autoridad del prelado (Ibid., p. 39).

35 THROOP, P.A. Criticism of the Crusade, Amsterdam, 1940, pp. 140-181. Cit. DEMURGER, $O b$. Cit., p. 229.

Sobre la Iglesia Medieval Hispania Sacra 49 (1997) 
de institutos religiosos que, haciendo de la violencia la razón misma de su existencia, entorpecian la labor terrenal y salvífica de la Iglesia.

Una velada crítica al respecto, ni siquiera escapó a la mođerada y pragmática prudencia de santo Tomás de Aquino, para quien las instituciones religiosas podían legítimamente prestar servicios militares en causas justificadas, pero no de forma sistemática sino en sustitución o representación de otros ${ }^{36}$. Quizá por ello, muy poco después, otro franciscano ilustre, el mallorquín Ramón Llull, en vísperas de la disolución del Temple, se atrevía a exponer un plan universal, contradictorio y cambiante, pero que, en un momento dado, colocaba bajo el control de un rex bellator a templarios y hospitalarios unidos en una nueva orden, la del Espíritu Santo, una orden, hasta cierto punto, algo más secularizada en su esencia funcional ${ }^{37}$.

36 Cit. NICHOLSON, ob. cit., p. 40. FOREY, The Military Orders, p. 204.

37 Garcia Palau, S. «Ramón Llull y la abolición de los templarios», en Hispania Sacra, 26 (1973), en especial pp. 4-7. 